-. 1969. Principles of phonology. Berkeley: Univ. of California Press. (English translation of Trubetzkoy 1939.)

Trzęsicki, Kazimierz. 1977. "Aksjomatyczne ujęcie teorii tekstu w związku z problematyką informacji naukowej". Zagadnienia informacji naukowej 1: $30.21-40$.

-. 1981. "Axiomatic text theories". Studies in logic, grammar and rhetoric. Vol. II. 70-83.

-. 1983. "Problem spójności tekstu w związku z aksjomatyczną teorią tekstu". Tekst i zdanie. Zbiór studiów ed. by Teresa Dobrzyńska \& Elżbieta Janus, 201-221. Wrocław: Zakład Narodowy imienia Ossolińskich \& Wydawnictwo Polskiej Akademii Nauk.

-. 1986. "Streszczanie jako operacja nad tematyczno-rematyczną strukturą tekstu”. Teoria tekstu. Zbiór studiów ed. by Teresa Dobrzyńska, 4153. Wrocław: Zakład Narodowy imienia Ossolinskich \& Wydawnictwo Polskiej Akademii Nauk.

-. 1990. "Tekst-fragment tekstu (Analiza formalna)". Teoria tekstu. Zbiór studiów ed. by Teresa Dobrzyńska, 135-144. Wrocław: Zakład Narodowy imienia Ossolińskich \& Wydawnictwo Polskiej Akademii Nauk.

Uspenskij, V. A. 1964. "Odna model' dlja ponjatija fonemy". Voprosy Jazykoznanija 13:6.39-53.

Vennemann, Theo. 1978. "Universal syllabic phonology". Theoretical Linguistics 5:2,3.175-215.

-. 1982. "Remarks on grammatical relations". Linguistics in the morning calm, 233-267. Seoul: Hanshin Publishing Company.

Wall, Robert. 1972. Introduction to mathematical linguistics. Englewood Cliffs, N. J.: Prentice Hall.
Wang, Jün-Tin. 1971a. "Zu den Begriffen der grammatischen Regel und der strukturellen Beschreibung". Probleme und Fortschritte der Transformationsgrammatik ed. by Dieter Wunderlich, 57-71. München: Hueber.

-. 1971b. "Zur Beziehung zwischen generativen und axiomatischen Methoden in linguistischen Untersuchungen”. Beiträge zur generativen Grammatik ed. by Arnim von Stechow, 273-282. Braunschweig: Vieweg.

-. 1972. "Wissenschaftliche Erklärung und generative Grammatik". Linguistik 1971. Referate des 6. linguistischen Kolloquiums 11-14 August 1971 in Kopenhagen ed. by K. Hylgaard-Jensen, 50-66. Frankfurt/M.: Athenäum.

-. 1973. "On the representation of generative grammars as first-order theories". Logic, language and probability ed. by J. Radu \& I. Niiniluoto, 302-316. Dordrecht: Reidel.

Wedberg, Anders. 1964. "On the principles of phonemic analysis". Ajatus. Suomen Filosofisen Yhdistyksen Vuosikirja 26.235-253.

Wojtasiewicz, Olgierd. 1962. "Towards a general theory of sign systems. I". Studia Logica 13.81101. (Repr. in Lingua osnaniensis 40. 1-23 [1998].) Wolniewicz, Bogusław. 1985. Ontologia sytuacji. Warszawa: Państwowe Wydawnictwo Naukowe.

Wunderlich, Dieter. 1969. "Karl Bühlers Grundprinzipien der Sprachtheorie". Muttersprache 79.52-62.

Zgółka, Tadeusz. 1976. O strukturalnym wyjaśnianiu faktów językowych. Warszawa \& Poznań: Państwowe Wydawnictwo Naukowe.

Jerzy Bańczerowski, Poznań (Poland)

\title{
217. Early formalization tendencies in 20th-century American linguistics
}

\author{
1. Introduction \\ 2. Formalization Stage 1 \\ 3. Formalization Stage 2 \\ 4. Formalization Stage 3 \\ 5. Formalization Stage 4 \\ 6. Bibliography
}

\section{Introduction}

Formalization, provided it is done properly and with good judgment, is the crowning achievement of science. Unfortunately, many linguists have a tendency to jump to formalizations prematurely, mistakenly thinking that only fully formalized theories can make a contribution to science. This unwise attitude explains a great deal of the theoretical myopia witnessed during the last century. Formalization is the last step in a long process of finding one's feet and getting one's bearings, of cautious exploration and ground testing, of becoming familiar with the object of enquiry and discovering possible generalizations and causal connections. Those who 
insist on full formalization straight away show that they have little idea of what real science amounts to.

On the other hand, those who reject any attempt at formalization are equally unwise. Marshaling one's findings into a formal theory with predictive power is the ultimate goal of all serious research, whether in the physical or in the social sciences. As regards the latter, the mathematical turn of the last century has led to such improvements in the clarity and systematicity of thinking in the traditional human sciences that it can no longer be rejected with impunity. A sensible middle course should, therefore, be followed. On the one hand, the available facts should be scrutinized as completely and as impartially as is feasible given the circumstances. On the other hand, the results should, at the right moment, be cast into an appropriately formalized framework or theory.

\section{Formalization Stage 1}

When speaking of formalization in science, one may distinguish several stages. We will distinguish four. Stage 1 consists in the typing or categorizing of the observed data and their representation in terms of a particular notational system or format. This format singles out certain parameters, other properties of the data being considered irrelevant for the purpose at hand. It reduces the observed unique token occurrences to types which can be multiply instantiated. The earliest form of formalization in linguistics consisted in the invention of writing systems. A writing system or orthography abstracts from all kinds of properties of token speech utterances and singles out those parameters that are essential for the prime function of language, the public undertaking of a commitment by the speaker with regard to a possible state of affairs. Seen from this angle, the invention of writing, which occurred some five thousand years ago, is a major intellectual achievement.

\section{Formalization Stage 2}

Stage 2 in the process of formalization consists in the setting up of a systematic charting or taxonomy of available data according to some criterion. Some taxonomy is necessary for any form of typing or categorizing as described above. Hence the Stages 1 and 2 often go hand-in-hand for some level of analysis.
To develop an orthography, for example, one must first set up a taxonomy of significantly differing classes of speech sounds (phonemes). However, in certain phases in the development of a science, the taxonomy of data, in the sense of setting up complete inventories of large data complexes, becomes a major or even prime concern. It is then that we speak of Stage 2 formalization.

In linguistics, the setting up of a systematic taxonomy of the world's languages began in the late 18 th century, as a direct consequence of the colonial expansion of the European nations. In the 19th and 20th centuries, this kind of taxonomy played an important role in the collection and description of native American languages, an activity that is still continuing. Language taxonomy is a major feature of modern typological linguistics, which is defined by the effort of singling out those features that characterize a language as belonging to a specific group or type. Largescale, computer-based projects are now under way in various parts of the world to classify and categorize the languages of the world.

\section{Formalization Stage 3}

Stage 3 consists in the assigning of structure to the data observed and recorded. The beginning of Stage 3 formalization in linguistics lies in Greece during the late 5th century BC, when philosophers, soon followed by language teachers, distinguished subject and predicate as the primary constituents of sentences. These structural analyses were refined through the subsequent centuries, until, in the early 20th century, the assignment of structure became the prime concern of American structuralist linguistics.

The prime mover, in this respect, was Leonard Bloomfield (1887-1949), who drew his inspiration mainly from the German philosopher-psychologist Wilhelm Wundt (cf. Percival 1976). In various publications (Wundt 1880: 53-71; 1922[1900]: 320-355; 1901: 71$82)$, Wundt proposed that both psychological and linguistic structures should be analyzed according to the principle of hierarchical constituency, corresponding to the modern notion of tree structure or immediate constituent analysis (IC-analysis). The earliest source is Wundt (1880: 53-54; translation mine):

The simplest form of a thought, i.e. a self-contained apperceptive representational process, occurs when a total representation ('Gesamtvorstel- 
lung') falls into two parts that are connected with each other. This happens in the simple judgement. If we use the sign - for apperceptive connections of successive representations, then $\widehat{\mathrm{AB}}$ is the psychological symbol of the simple judgement.

As soon as the total representation, the splitting up of which results in a thought process, is separated into three or more single representations, the judgement is no longer simple but composite. In a composite judgement the connection of the single parts is never uniform, in the sense that the form $\widehat{\mathrm{AB}}$ would extend over a larger number of members, as in $\widehat{\mathrm{ABC}} \mathrm{C}[\ldots]$. On the contrary, these apperceptive connections always proceed in such a way that first, as with the simple thought, the total representation is separated into two single representations, upon which either or both of these can be subdivided into two further single representations, and so on. Herein lies the essential difference between apperceptive and associative connections. If we use the sign - for the associative connection of successive representations, we see that an associative sequence $\mathrm{A}^{-} \mathrm{B}^{-} \mathrm{C}^{-} \mathrm{D}[\ldots]$ can contain any number of members. In contrast to this, the apperceptive thought process always proceeds in forms like the following:
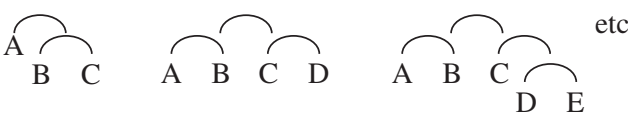

Fig. 217

This principle of duality or of binary connection has found its unmistakable expression in the categories of grammatical syntax. For all these categories always reduce to just two representations which are connected with each other. Thus we distinguish first the two main representations Subject and Predicate, which correspond with the first division of the thought. The Subject may be divided again into Noun and Attribute. The Predicate, when it is nominal, splits into the Copula and the Predicate proper, upon which the latter, like the Subject, may split into Noun and Attribute again. But if the Predicate is verbal it may split into Verb and Object, or into the Predicate proper and the supplementary Predicate.

(One sees that Wundt professes a preference for strictly binary branchings. To him, multiply branching structures were a sign of a primitive mind.)

In Wundt (1900: 320-355) the constituents of the tree structures are labeled, as shown in Fig. 217.1 (Wundt 1900: 329). ('G' stands for 'Gesamtvorstellung', expressed as a full sentence.)
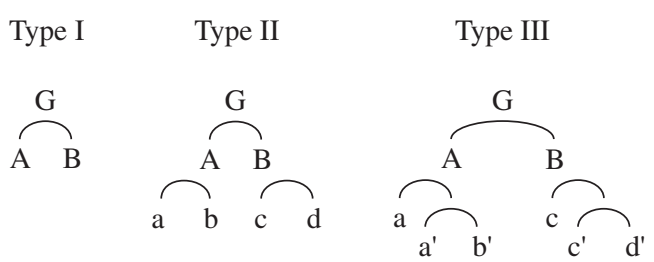

Fig. 217.1: Wundt's labeled treesy

In his first introductory textbook on linguistics, Bloomfield followed Wundt closely. The only clear difference between him and Wundt lay in Bloomfield's disinclination to actually draw tree diagrams, no doubt due to a deeply ingrained reluctance to adopt formalizing procedures in the human sciences. In fact, neither in his (1914) nor in his later book (1933), or in any of his other writings, did Bloomfield draw a single tree structure, even though the notion of hierarchically ordered constituent trees permeates most of his work. We read (Bloomfield 1914: 110):

When the analysis of experience arrives at independently recurring and therefore separately imaginable elements, words, the interrelations of these in the sentence appear in varied and interesting linguistic phenomena. Psychologically the basis of these interrelations is the passing of the unitary apperception from one to the other of the elements of an experience. The leading binary division so made is into two parts, subject and predicate, each of which may be further analyzed into successive binary groups of attribute and subject, the attribute being felt as a property of its subject.

In the early 1920s Bloomfield turned away from Wundtian psychology and embraced the then brand new ideology of behaviorism. Yet the Wundtian notion of constituent structure remained and even became more and more central to Bloomfield's thinking about language. It is the central notion in the theory of grammar presented in the chapters 10 to 16 of his (1933).

The linguist-anthropologist Sapir (18841939) followed Bloomfield (1914) in his book Language of 1921, again showing a remarkable reluctance to resort to the actual drawing of diagrams (Sapir 1921: 31-32):

One example will do for thousands, one complex type for hundreds of possible types. I select it from Paiute, the language of the Indians of the arid plateaus of southwestern Utah. The word wii-tokuchum-punku-rügani-yugwi-va-ntü-m( $\ddot{u})$ is of unusual length even for its own language, but it is no psychological monster for all that. It means "they 


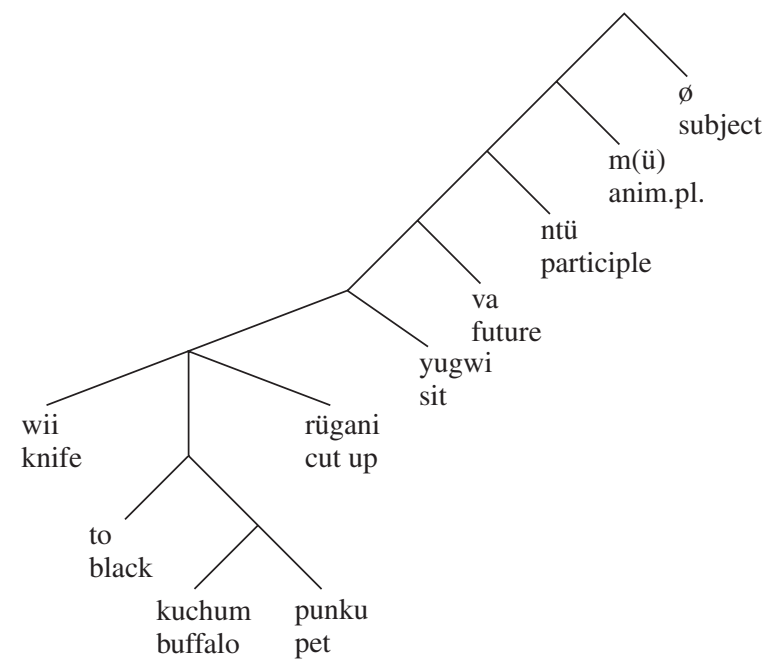

Fig. 217.2: Immediate constituent analysis of the Paiute word wii-to-kuchum-punku-rügani-yugwi-va-ntü-m(ü)

who are going to sit and cut up with a knife a black cow (or bull)", or, in the order of the Indian elements, "knife-black-buffalo-pet-cut up-sit(plur.)future-participle-animate-plur". The formula for this word, in accordance with our symbolism, would be $(\mathrm{F})+(\mathrm{E})+\mathrm{C}+\mathrm{d}+\mathrm{A}+\mathrm{B}+(\mathrm{g})+$ (h) $+(\mathrm{i})+(0)$. It is the plural of the future participle of a compound verb "to sit and cut up" A + B. The elements $(g)$ - which denotes futuricity (h) - a participial suffix - and (i) - indicating the animate plural - are grammatical elements which convey nothing when detached. The formula $(0)$ is intended to imply that the finished word conveys, in addition to what is definitely expressed, a further relational idea, that of subjectivity; in other words, the form can only be used as the subject of a sentence, not in an objective or other syntactic relation. The radical element A ("to cut up"), before entering into combination with the coordinate element B ("to sit"), is itself compounded with two nominal elements or element-groups - an instrumentally used stem (F) ("knife"), which may be freely used as the radical element of noun forms but cannot be employed as an absolute noun in its given form, and an objectively used group - (E) $+\mathrm{C}+\mathrm{d}$ ("black cow or bull"). This group in turn consists of an adjectival radical element (E) ("black"), which cannot be independently employed [...] and the compound noun $\mathrm{C}+\mathrm{d}$ ("buffalo-pet"). The radical element $\mathrm{C}$ properly means "buffalo", but the element d, properly an independently occurring noun meaning "horse" [...], is regularly used as a quasi subordinate element indicating that the animal denoted by the stem to which it is affixed is owned by a human being. It will be observed that the whole complex $(\mathrm{F})+(\mathrm{E})+\mathrm{C}+$ $\mathrm{d}+\mathrm{A}+\mathrm{B}$ is functionally no more than a verbal base, corresponding to the sing- of an English form like singing; that this complex remains verbal in force on the addition of the temporal element $(\mathrm{g})$ this $(\mathrm{g})$, by the way, must not be understood as appended to $\mathrm{B}$ alone, but to the whole basic complex as a unit - and that the elements (h) + (i) + (0) transform the verbal expression into a formally well-defined noun.

Had Sapir simply drawn a tree diagram, the result would have been the much more informative, mainly left-branching constituent tree structure of Fig. 217.2 (above).

Tree structures (provided they do not have discontinuous constituents) can be represented also as one-dimensional strings of symbols with a so-called 'bracketing' structure. Labeling of the bracket pairs then corresponds to the labeling of the constituent nodes. A form of unlabeled bracketing was used in Wells (1947), where the structure of the English sentence (1a) is represented as (1b)

(1a) The king of England opened Parliament.

(1b) The || king ||| of |||| England | open ||| ed $\|$ Parliament

The first actually drawn tree diagram in the American linguistic literature, still with unlabeled constituent nodes, is in Nida (1949: 87), reproduced here as Fig. 217.4.

Chomsky (1957) contains just one tree diagram (p. 27). It was not until the late 1950s that the convention was established of drawing tree diagrams in the format that is now generally accepted, i.e., with labeled nodes and from the root down. 


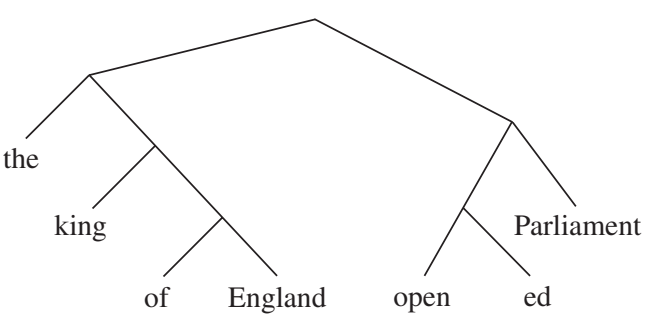

Fig. 217.3: The king of England opened Parliament (according to Wells 1947)

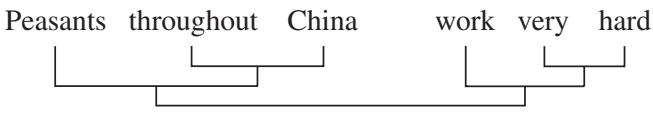

Fig. 217.4: IC-diagram in Nida (1949: 87)

That tree structure analysis has been so successful in linguistics may be explained not only by its intuitive appeal but also by the fact that tree diagrams provide an ideal framework for computation procedures of all kinds. An illustration for the arithmetical computation of $(5 \times 6)+8$ and $5 \times(6+8)$, respectively, is given in Fig. 217.5 (see Seuren 1998: 225). One branch is interpreted as a function, the remaining branch or branches are interpreted as input to the function. The dominating node is interpreted as the resulting value.
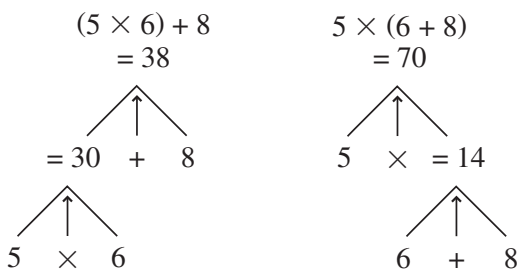

Fig. 217.5: Constituency trees for simple arithmetic

The Frenchman Lucien Tesnière (18931954) introduced a different type of tree structure, the so-called dependency trees, which place the function in the position of the dominating node and presents the input as its branches. These trees, however, though much used in mathematics and also in some European schools of linguistics, have had no career in American structuralism. (For further elaboration, see Seuren 1998: 225-227.)
The technique of tree structure assignment developed by Bloomfield and applied by his followers and students inevitably gave rise to the vital question of what motivates the selection of any particular tree structure assignment. On what grounds should one structure assignment be considered better than another? To give a concrete example, till the present day linguists are divided over the issue of which of the two structure assignments for the same sentence I reckon the man to be a swindler should be considered to be the correct one, $(2 \mathrm{a})$ or $(2 \mathrm{~b})$.

(2a)

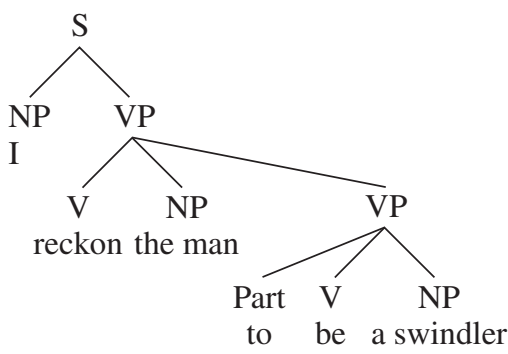

(2b)

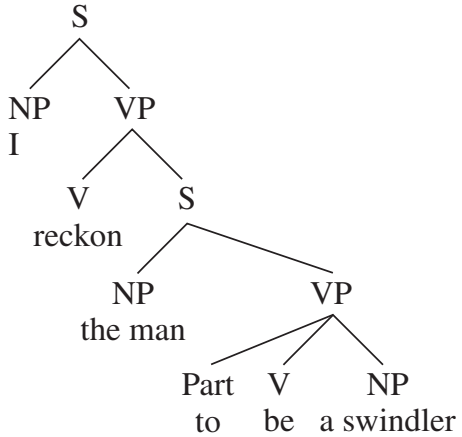

Bloomfield himself never answered this question. Some among his followers, notably Kenneth L. Pike and his circle of missionarylinguists, proposed that an appeal to introspection would suffice: one somehow 'feels' what the right structure assignment is. These so-called 'God's truth' linguists, however, did not carry the day. Their opponents, headed by Zellig Harris, came with a totally different answer, which involved a stepping up of the level of formalization, for which reason they were nicknamed 'hocus pocus' linguists by Fred Householder reviewing Harris (1951).

\section{Formalization Stage 4}

It was Zellig Sabbettai Harris (1909-1992) who provided the first principled answer to the question of what motivates tree structure 
assignments. His answer involved a stepping up of the level of formalization of linguistic theory. In his magnum opus of 1951 he demonstrates a progress of formalization from the stages (1), (2) and (3) to the final Stage 4, which consists in the setting up of a formal predictive and explanatory theory that has the precision of an algorithmic procedure.

The book, which reflects work done during the mid-1940s, starts with an exposé on how to categorize and record token speech sounds (Stage 1). From there it proceeds to present a method for grouping them into wider, more abstract descriptive categories called phonemes. In Harris's perspective, this step is made possible by a careful charting of the positions in which the token sounds occur, their distribution (Stage 2). Whenever two different speech sound types never fill the same position but are each reserved for one or more specific positions, they are said to be in complementary distribution, which, in Harris's view, justifies their subsumption under one single, higher-level descriptive unit or category. This is a feedback operation involving the Stages 1 and 2.

When it is found that members of two or more categories typically co-occur in a fixed order in the corpus of utterances, they may be tentatively classified as forming a composite unit. Thus, typical co-occurrences of phonemes yield units called 'morphemes'. Morphemes are again subsumed under morpheme classes, according to their occurrence patterns, and typical co-occurrences of morpheme classes are again taken to yield higher order units, or constructions. The repeated application of this method of analysis is thus supposed to lead straight up to structure assignments for all the utterances of a given corpus (Stage 3). If done in the most efficient possible way, it is taken to provide the most economical assignment of structure to speech utterances. Harris's method thus provides a discovery procedure for grammars that assign structure to sentences. This discovery procedure is an elaborate form of Stage 3 formalization.

Since structures thus assigned are of the constituent tree structure type, Harris's method provides, at the same time, a principled answer to the question of what motivates tree structure assignments: those tree structure assignments are optimal which result from the most economical possible application of Harris's method of analysis. By giving this answer, Harris deflected the attention from individual cases to the overall system of structure assignments. At the time, this perspective was experienced as startlingly new and daring.

Similar attempts at a discovery procedure for well-motivated structure assignments, often reflecting the same general ideas that underlay Harris's work, were made by others during the period in question, in particular by Wells (1947), Bloch (1948), Hockett (1947, 1952). It was, however, the approach set out in Harris (1951) that has proved to be the most influential, mainly, and paradoxically, because it was so obviously unrealistic and impractical: one could hardly imagine any linguist actually applying Harris's convoluted and labour-intensive method to any given corpus of utterances.

Harris himself was sensitive to the charge of impracticability. For that reason he proposed, towards the end of the book, that the results of the work of analysis as proposed by him should be brought together into what he called a deductive system of synthetic statements, thereby laying the foundation for what was soon to be known as 'Generative Grammar'. He writes, still in a somewhat stilted terminology (Harris 1951: 372-373):

The work of analysis leads right up to the statements which enable anyone to synthesize or predict utterances in the language. These statements form a deductive system with axiomatically defined initial elements and with theorems concerning the relations among them. The final theorems would indicate the structure of the utterances of the language in terms of the preceding parts of the system.

It did not take him long to realize that one might then just as well start at the 'synthetic' or generative end by formulating hypotheses about the deductively organized 'synthetic statements' that would 'predict utterances in the language'. These hypotheses could then be tested for factual correctness and for maximal generality and efficiency, which would make the 'work of analysis' unnecessary and thus save time as well as make the linguist's work more practical and intellectually more exciting. This realization marked the beginning of the period of Generative Grammar, which meant a definite paradigm shift in the study of language. In fact, it marked a transition to stage 4 formalization.

It was, however, not Harris but his student Noam Chomsky who ushered in the new paradigm with his little book (1957). In Syntactic Structures, Harris's discovery procedure is 
skipped. Instead, the linguist is advised to start with the setting up of an overall hypothesis of structure assignments for the language in question in the form of a set of algorithmically (i.e., deductively) organized production rules, called Phrase Structure rules or PSrules which generate sentences while simultaneously assigning them a constituent tree structure or PS-structure. In Chomsky's own words (1957: 56):

In short we shall never consider the question of how one might have arrived at the grammar whose simplicity is being determined. [...] Questions of this sort are not relevant to the program of research that we have outlined above. One may arrive at a grammar by intuition, guess-work, all sorts of partial methodological hints, reliance on past experience, etc. [...] Our ultimate aim is to provide an objective, non-intuitive way to evaluate a grammar once presented, and to compare it with other proposed grammars. We are thus interested in describing the form of grammars (equivalently, the nature of linguistic structure) and investigating the empirical consequences of adopting a certain model for linguistic structure, rather than in showing how, in principle, one might have arrived at the grammar of the language.

Once the notion of an algorithmic (or deductive or generative) grammar had been accepted, it began to make sense to look at the overall organization of such grammars. Harris soon found - an insight immediately taken over by his student Chomsky - that it would make obvious sense to distinguish two components in the grammar of a language. The first component, now generally known as 'Formation Rules' or 'PS-Grammar', generates structures from scratch (symbolized as the starting symbol ' $S$ '). Subsequently, the second component, known as Transformational Component or T-Rules, takes one or more products of the PS-Grammar and transforms these into a surface structure.

The motivation for this distinction is a simple insight that goes back at least to the 16th-century Spanish linguist and philosopher of language Sanctius (see Seuren 1998: 41-46) and has had a constant though not always overt influence on grammatical thinking till the present day. It is the insight that there are systematic relations between sentence structures of different types, such as between active and passive sentences, between assertions and questions, between affirmative and negative sentences, and so on. The question was (and is) how to make best use of these correspondences so as to produce a grammar with the simplest overall structure and the widest possible generalizations.

The first suggestion was to let the PSGrammar generate simple sentences, the socalled kernel sentences, to which transformational rules can be applied to generate the more complex variants. This 'horizontal' idea of transformations was soon abandoned, by both Harris and Chomsky, in favor of a 'vertical' notion, which implied that the PSGrammar would generate a so-called deep structure (DS) for every sentence. The DS would serve as the input to the transformational component, which would transform the DS into a corresponding surface structure (SS). Soon a further Phonological Component was added to account for the proper phonetic form of the sentence generated. The resulting concept of grammar became known as Transformational Generative Grammar or TGG.

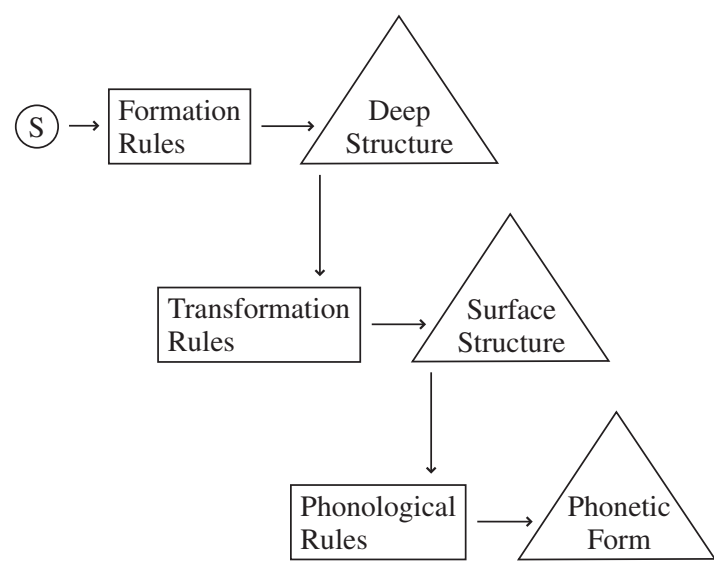

Fig. 217.6: The overall structure of a TGG around 1960 
The PS-Grammar may be seen as a primitive algorithm, generating strings from scratch. The T-Rules form a derived algorithm, taking the structures generated by a preceding, primitive or derived, algorithm as input and producing an output transformed according to certain rules and principles (see Seuren 1998: 267-279, for ample comment).

In the context of contemporary philosophy of science, it became customary, just after 1960 , to see a TGG as an explicit formal theory of the intuitive notion of speaker's linguistic competence. It was felt that 'competence in a language' amounts to the ability to produce and analyze ('parse') syntactically well-formed sentences. However, no sooner was this notion mooted than it was realized that, of course, linguistic competence involves a great deal more than just the ability to produce and analyze well-formed sentences. To be competent in a language involves the ability to understand or interpret sentences as well.

This led to the proposal (Katz \& Fodor 1963) to add a Semantic Component to the grammar, that would, somehow, 'interpret' the syntactic structures, both DS and SS, producing a 'semantic representation', even though it was unclear how exactly that should be done or what a 'semantic representation' should look like. In Katz \& Postal (1964) arguments were presented to show that this proposal should be modified in the sense that the Semantic Component should take the DS of any sentence as the sole input, so that the whole semantic interpretation process would come to depend on the DS. It was argued that the SS should be seen as the mere surface representative of the meaning fixed at DS level.

Subsequently, during the mid-1960s, many linguists in America and some in Europe, realized that this view in fact made the entire Semantic Component redundant, since there was no good argument to distinguish any longer between the DS and the, hitherto unclear, notion of semantic representation. This ushered in the period of Generative Semantics, about which more in the article on 'Sentence-oriented semantic approaches in generative grammar'.

This concludes the discussioin of early formalization tendencies in American linguistics. From the 1970s onwards, other schools of linguistic thought, in particular Montague Grammar, Categorial Grammar, and Headdriven Phrase Structure Grammar, have pro- duced elaborate formalized systems for the analysis and description of sentences, complete with their semantic properties. These, however, fall outside the scope of the present article.

\section{Bibliography}

Bloch, Bernard. 1948. "A Set of Postulates for Phonemic Analysis”. Language 24: 1.3-46.

Bloomfield, Leonard. 1914. An Introduction to the Study of Language. New York: Holt \& Co. (Repr., with an Introduction by Joseph F. Kess, Amsterdam \& Philadelphia: Benjamins, 1983.)

Bloomfield, Leonard. 1933. Language. New York: Holt \& Co.

Chomsky, Noam. 1957. Syntactic Structures. (= Janua Linguarum, 4.) The Hague: Mouton.

Dixon, Robert M. W. 1982. Where Have All the Adjectives Gone? and Other Essays in Semantics and Syntax. Berlin, Amsterdam \& New York: Mouton.

Fillmore, Charles J. 1971. "Types of Lexical Information”. Steinberg \& Jakobovits, eds. 1971. 370392.

Harris, Zellig S. 1951. Methods in Structural Linguistics. Chicago: University of Chicago Press.

Hockett, Charles F. 1947. "Problems of Morphemic Analysis". Language 23: 3.321-343. (Also in Joos, ed. 1957. 229-242.)

Hockett, Charles F. 1952. "A Formal Statement of Morphemic Analysis". Studies in Linguistics 10: $1.27-39$.

Joos, Martin, ed. 1957. Readings in Linguistics: The development of descriptive linguistics in America since 1925. Washington: American Council of Learned Societies.

Katz, Jerrold J. \& Jerry A. Fodor. 1963. "The Structure of a Semantic Theory". Language 39: $2.170-210$.

Katz, Jerrold J. \& Paul M. Postal. 1964. An Integrated Theory of Linguistic Description. Cambridge, Mass.: MIT Press.

Kiparsky, Paul \& Carol Kiparsky. 1971. "Fact". Steinberg \& Jakobovits, eds. 1971. 345-369.

Nida, Eugene A. 1949 [1946 $]$. Morphology. The Descriptive Analysis of Words. Ann Arbor: The University of Michigan Press.

Percival, W. Keith. 1976. "On the Historical Source of Immediate Constituent Analysis. Notes from the Linguistic Underground ed. by James D. McCawley. (= Syntax and Semantics, 7), 229-242. 
New York, San Francisco \& London: Academic Press.

Quine, Willard V. O. 1960. Word and Object. Cambridge, Mass.: MIT Press.

Rosch, Eleanor. 1975. "Cognitive Representations in Semantic Categories". Journal of Experimental Psychology: General 104.192-233.

Sapir, Edward. 1921. Language: An introduction to the study of speech. New York: Harcourt, Brace \& Co.

Seuren, Pieter A. M. 1996. Semantic Syntax. Oxford: Blackwell.

Seuren, Pieter A. M. 1998. Western Linguistics: An historical introduction. Oxford: Blackwell.

Steinberg, Danny D. \& L. A. Jakobovits, eds. 1971. Semantics: An interdisciplinary reader in philosophy, linguistics and psychology. Cambridge: Cambridge University Press.

Wells, Rulon S. 1947. "Immediate Constituents". Language 23: 1.81-117. (Also in Joos, ed. 1957: 186-207.)

Wundt, Wilhelm. 1880. Logik: Eine Untersuchung der Prinzipien der Erkenntnis und der Methoden wissenschaftlicher Forschung. Stuttgart: Enke.

Wundt, Wilhelm. 1901. Sprachgeschichte und Sprachpsychologie. Mit Rücksicht auf B. Delbrücks "Grundfragen der Sprachforschung". Leipzig: Engelmann.

Wundt, Wilhelm. 1922 [1900]. Völkerpsychologie: Eine Untersuchung der Entwicklungsgesetze von Sprache, Mythus und Sitte. Vol. II: Die Sprache, Part 2. 4th ed. Leipzig: Kröner.

Pieter Seuren, Nijmegen (The Netherlands)

\section{On the origins and early developments of Chomskyan linguistics: The rise and fall of the standard model}

1. Introduction

2. Language as a rule-governed system

3. Emphasis on structure and on competence

4. Typical components

5. Constraints on transformations

6. Conclusion

7. Bibliography

\section{Introduction}

At the heart of Chomskyan linguistics is a research program called generative grammar. Generative grammar originated in work done by Noam Chomsky (b. 1928) during a research fellowship at Harvard University in the early 1950s. By the end of the 20th century, generative grammar had followers all over the world, and Chomsky had become one of the most cited living researchers (v. Otero 1994: I.xxii). While transformational analysis actually originated at the University of Pennsylvania with Chomsky's advisor, Zellig Harris, generative grammar has always been closely associated with Chomsky, his students and the university where Chomsky has taught, the Massachusetts Institute of Technology (MIT). From its inception, generative grammar has remained a fast-moving, controversial research effort, characterized by a largely invariant core of metaphysical and methodological principles, but with fre- quent modifications in its implementation details. This article briefly traces the development of the 'standard model' of generative grammar from its origins in the $1950 \mathrm{~s}$ through its decline in the early 1970s.

\section{Language as a rule-governed system}

One central claim of Chomskyan linguistics is that natural language can be described as a regular, rule-governed system whose combinatory characteristics can be discovered and studied. This was a bold claim to make in the 1950s, when the syntax of natural languages, like many other aspects of human knowledge and behavior, was commonly believed to be too irregular to be susceptible to rigorous treatment. Yet the claim was not entirely novel, as one finds precedent in structural linguistics, which emphasized making theories as compact and explicit as possible. Louis Hjelmslev (1899-1965), for example, suggested that linguistics, as one of the sciences, must seek a "general and exhaustive calculus" of its subject matter (1961 [1943]: 9), both arbitrary and appropriate. A few years later, Zellig Harris (1909-1992) wrote that linguistic analysis should include a "deductive system with axiomatically defined initial 